\title{
In Memoriam: Peter A. Miescher, 1923-2020
}

\section{Shozo Izui ${ }^{1}$ - Jürg A. Schifferli ${ }^{2}$}

Published online: 30 June 2020

(C) Springer-Verlag GmbH Germany, part of Springer Nature 2020

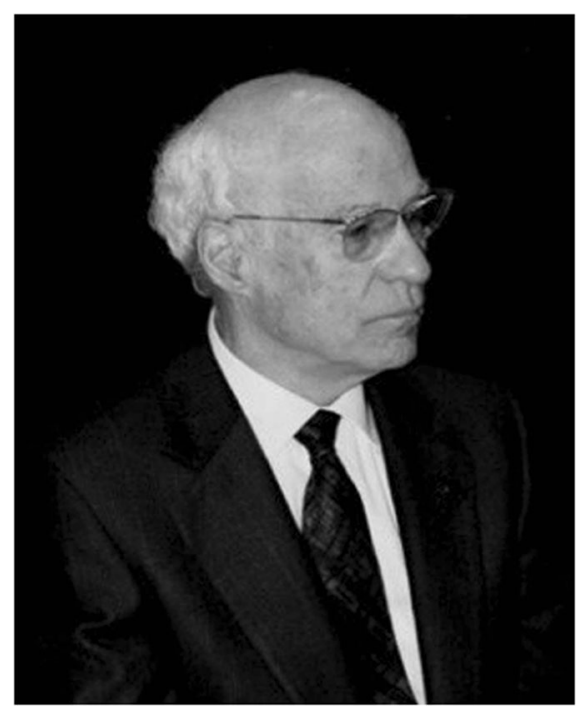

Peter A. Miescher, a founding editor of Seminars in Immunopathology (initially called Springer Seminars in Immunopathology), died in Locarno, Switzerland, on May 14, 2020, at the age of 96.

Peter Miescher had a fascination for autoimmune diseases, in particular systemic lupus erythematosus (SLE). Already in 1953 , he published a paper on the "immune-nucleo-phagocytosis", known as the LE phenomenon. His major achievement was to demonstrate in 1957 that DNA was one of the targets of anti-nuclear autoantibodies whilst he was working at the University Hospital in Basel, Switzerland. After his clinical training, he went to New York where he stayed many years and worked with Professor Bajul Bennacerraf (Nobel prize winner 2000) on immune mechanisms responsible for efficient phagocytosis, including the complement system. At that time,

Shozo Izui

Shozo.Izui@unige.ch

1 Geneva, Switzerland

2 Basel, Switzerland
Hans Müller-Eberhard was also working on complement and immune mechanisms in New York at the Rockefeller Institute, Mount Sinai Hospital. They became friends, but both moved in two different directions; Müller-Eberhard went to La Jolla, California, starting to define the molecules of the complement cascade and Peter Miescher came back to Switzerland in 1968 as Professor of Haematology at the University of Geneva. He continued to develop his interests in the pathological and clinical aspects of autoimmunity. One of his post-docs was Shozo Izui and one of his students was Jürg Schifferli.

In 1978, Peter Miescher together with old friend Hans Müller-Eberhard decided to start a review journal: the "Springer Seminars in Immunopathology" now renamed "Seminars in Immunopathology". Both served as Editors-inChief during many years until the death of Hans MüllerEberhard (1998), then Peter Miescher continued to develop the journal until the position was passed on to new leadership in 2005 (the undersigned). Seminars in Immunopathology was founded with the aim of keeping clinicians and pathologists up-to-date on new developments in the field of immunopathology. Under Peter Miescher's hand, Seminars in Immunopathology rapidly rose to become one of the highest impact immunopathology publications, a position it has maintained until the present time.

The understanding of the pathogenic mechanisms of the disease with immunopathological consequences is essential for setting up rational treatment regimens. Research to define the molecular events in the immune response progresses so rapidly that most clinicians have problems keeping up with developments. Nowadays, the immune response is at the centre of clinical immunology, and understanding it is essential and indispensable for establishing rational treatment regimens. Having had 60 years of experience in the development and application of flexible treatment protocols, Peter Miescher continued his clinical activities as consultant to various groups of physicians at the university clinics of Rome and Parma since leaving Geneva University Hospital in 1994. We would like to mention his own contribution, entitled "Autoimmune Disorders: A Concept of Treatment Based on Mechanisms of Disease" to 
Seminars in Immunopathology at the opportunity of the 25th anniversary of the founding of Seminars in Immunopathology in 2003. In this article, he conveyed his vast personal experience in the polypharmacological management of autoimmune diseases to physicians engaged in the treatment of such disorders.

On a personal note, Peter Miescher was an exceptionally talented researcher, with many very original ideas he liked to discuss with his research group, with clinicians at the University Hospital in Geneva and at international meetings.
We would like to express our sincere appreciation for Peter Miescher to establish Seminars in Immunopathology as one of the most unique and important publications in the field of immunopathology.

Publisher's note Springer Nature remains neutral with regard to jurisdictional claims in published maps and institutional affiliations. 